\section{Sagan breached security by revealing US work on a lunar bomb project}

Sir - In his review of two biographies of Carl Sagan, by William Poundstone and by Keay Davidson (Nature 401, 857; 1999), Christopher Chyba deals extensively with "Davidson's accusation that the young Sagan wilfully and illegally revealed classified information..." and further states: "This is a serious and specific legal allegation which Davidson does not substantiate".

The classified project involved, Project A119, entitled A Study of Lunar Research Flights (SECRET), was conducted at Armour Research Foundation (ARF) while I was manager of physics research. I was also leader of the project, so Sagan reported directly to me. I, therefore, feel obliged to extend the historical record beyond the Davidson biography by offering some additional, first-hand comments.

A119 was one of a series of projects conducted at ARF under my direction from 1949 to 1962 , all concerned with the global environmental effects of nuclear explosions and related phenomena. Some time before May 1958, we were asked by the US Air Force to add a small, fast-track project to investigate the visibility and effects of a hypothetical nuclear explosion on the Moon. I was told the Air Force was very interested in the possibility of a surprise demonstration explosion, with all its obvious implications for public relations and the Cold War.

Whether the project was motivated by a desire for the United States to impress the world (and the Soviet Union in particular), or by fear that the Soviet Union itself might try the stunt, I cannot say. It was emphasized, however, that the most sensitive aspect of the project was, as with many other Department of Defense projects, its very existence. Hence it was given a separate name and work on it was classified as secret. Our task was to assess what gross visible and other phenomena might be generated by the explosive release on the lunar surface of a given number of kilotonnes of energy.

We were also asked to try to determine what legitimate scientific data might be gathered from such an event: for example, about lunar chemistry. The cost to science of destroying the pristine lunar environment did not seem of concern to our sponsors - but it certainly was to us, as I made clear at the time.

In staffing A119, I realised that we needed expertise in planetary physics and asked Gerard P. Kuiper to act as our consultant. Kuiper agreed, and in time suggested that I hire a graduate student from Yerkes/
University of Chicago called Carl Sagan, who needed a job. I gave Sagan the assignment of mathematically modelling the expansion of an exploding gas/dust cloud rarifying into the space around the Moon. This was preliminary to attempts to calculate the visibility of such a cloud from Earth. Sagan had difficulty with the problem and consulted Kuiper several times before I brought in additional help. Sagan soon suggested that he should try to see how a nuclear explosion might be used to detect organic molecules on the Moon. I agreed to a brief effort in that direction.

Nine monthly progress reports, all classified as secret and including all of Sagan's work, were issued by ARF to the Air Force Special Weapons Center under Project A119 from May 1958 to January 1959. According to Armour (now the Illinois Institute of Technology Research Institute) archives, they were all destroyed after October 1987.

I did not know until the biographies were published that Sagan had sent an "unclassified" (by whom?) manuscript about his work on A119 to any unauthorized person - let alone to five people, as Chyba remarks. Both ARF's and Sagan's obligations under the A1 19 contract, as Sagan's signed security agreement would have clearly informed him, required Air Force clearance of any such revelations. As his boss at the time, I would have had to take forward any such request, and Air Force permission would have been extremely unlikely in those long-ago, very tense times.

In his review, Chyba argues that classified documents can contain unclassified titles or subsections. Perhaps so, but that misses the point. Fortunately for the future of lunar science, a one- or two-horse race to detonate a nuclear explosion never occurred. But in my opinion Sagan breached security in March 1959 when he revealed the ARF's classified projects on "possible lunar nuclear detonations" in his application for a Miller fellowship.

\section{Leonard Reiffel}

Exelar Corporation, 602 Deming Place, Chicago, Illinois 60614, USA

\section{Austria takes lab animal welfare seriously}

Sir - In response to the News report "Austria taken to court for inadequate laws on animal welfare" (Nature 403, 582; 2000), I would like to explain the legal situation. Animal experiments in Austria are regulated on the federal level by the Animal Experiments Act. Passed in 1989, well before Austria's accession to the European Union in 1995, this law was drawn up to conform with the Animal Experiment Directive (86/609/EEC), even though at that time Austria was not obliged to do so. The act was amended last year. Animal welfare is regulated at provincial level, and all nine provinces have animal welfare legislation.

The Animal Experiments Act empowers the competent Federal Ministers to regulate technical matters by ministerial ordinance. Ordinances laying down specific rules (for example, covering research centres that breed animals on their own premises) are currently under consultation. As soon as they come into force, the last minor deficiencies in transposing the Directive will have been eliminated.

\section{Wolf Frühauf}

Federal Ministry of Education, Science and Culture, Minoritenplatz 5, A-1014 Vienna, Austria

\section{How metrics could have saved UK car industry}

Sir - You recently featured a report, in the "100 years ago" column, (Nature 404, 27; 2000) on German iron manufacturing, written by the British consul in Amsterdam in 1900. He mentioned a uniform system of dimensions for articles of universal consumption, and a system of metric screw threads being fixed by a committee of engineers' associations. Unless Britain joined the metric standard, the consul warned, "Germany and the continent generally will have a constantly increasing advantage over British manufacturers". His words were prophetic -150 of the world's 190 export markets are now metric.

The engineers' associations agreed on the Système International (SI) of metric threads at a special meeting, the Congress of Zurich, in October 1898. This was to end the confusion caused by different European countries using different systems on their railways, though they didn't enter British consciousness until the Second World War, as BSI War Emergency Standard BS 1095:1943. The 1898 meeting also saw the birth of ISO metric standards for engineering, which entered the British standards environment in 1966 through a book published by the then Ministry of Technology.

Meanwhile, metric screw threads, standard diameters, shaft/hole fits and machining tolerances for the engineering industry had been internationalized during the 1920 s and 1930 s by a body called ISA, which was absorbed into ISO in 1946. The old SI metric thread with its undesirably sharp fillet radius was modernized by application of the unified profile by ISO in 1958 and standardized by all industrialized nations soon afterwards. That is why all mechanical engineering assemblies made in mainland European factories since 1959 
use the same threads up to $80 \mathrm{~mm}$ diameter.

In order to assure the free circulation of engineering components and subassemblies in the European Common Market, the UK government - led by Harold Wilson announced in May 1965 that British industry would abandon the inch within ten years and adopt ISO metric standards. The first attempt to produce a British engine to metric standards was already in progress at Leyland Motors with the Leyland 500 engine. However, this was marketed in continental Europe only in the Leyland National bus, whose full metrication was never completed: it incorporated four different screw-thread standards and was impossible to manage in European workshops.

British Leyland vehicles failed to attract continental dealers because the inch was already alien in mainland Europe - it had actually been outlawed in mechanical engineering in Germany during the 1930s. It remained only in water- and gas-pipes, and in certain items imported from the United States.

Inch threads had no future in Europe, but the planned conversion of British engineering factories did not occur. As a result, the UK's non-metric products were rejected by Europe as a nuisance.

It was the abandonment of Wilson's metrication programme, along with deficient marketing, that caused the stagnation of British Leyland and so many other engineering-based companies in the United Kingdom. The economic effects of Britain's failure to adopt the metric system on schedule have never been quantified. But the recent loss of the $\$ 125$ million NASA Mars Orbiter probe emphasizes the vast sums of money that can be lost through the unfamiliarity of the average UK or US technocrat with metric units.

Michael T. Knowles

11 Powlett Court, Bath BA2 6QJ, UK

\section{Instrument's ability to do the job is NASA's priority}

Sir - In your News profile article "Sky's the limit as teams bid for NASA Project" (Nature 403, 587; 2000), Colin Macilwain implies that NASA administrator Daniel Goldin's professed enthusiasm for particle physics detector technologies would be a factor in the selection of one of two competing instruments for the Gammaray Large Area Space Telescope Mission. (High-energy gamma-ray instrumentation has always drawn heavily from techniques developed for high-energy physics studies.) There is the further implication that contributions to the cost might also provide an advantage.

Although the winning team, from Stan- ford, contains particle physicists sponsored by the Department of Energy, this had no direct bearing on the selection. It is NASA's policy to select instruments for its missions through a peer-review process that evaluates first and foremost the proposed science and the proposed instrument's ability to achieve that science. There are other factors, but these do not include the participation of other partners, either foreign or domestic, unless they can help the team achieve their science goals.

Incidentally, your News profile stated that the competing instrument was from NASA's Marshall Space Flight Center (MSFC). Although MSFC did participate, along with several other institutions, the principal investigator was from the University of Alabama in Huntsville, and the proposal was submitted through the university. The selected instrument also included a team from NASA's Goddard Space Flight Center, as well as several other institutions, both domestic and foreign.

Donald A. Kniffen

NASA Headquarters, Office of Space Science, Research Program Management Division, Washington DC 20546, USA

\section{Putting marine mammals back in the mainstream}

Sir-I read with interest Vaclav Smil's Millennium Essay ${ }^{1}$, in which he describes the general importance to bioenergetics of Max Kleiber's studies on the scaling relationship of metabolic rate with body mass in animals. Across 18 orders of magnitude from unicellular organisms to whales, it seems metabolic rate is proportional to body mass raised to the power of 0.75 ; the so-called three-quarters rule, exemplified by the wellknown mouse-to-elephant curve.

Smil gives the example of marine mammals as species whose metabolic rates lie outside this relationship because, apparently, seals and whales have basal metabolic rates (BMR) about twice as high as those of other animals their size, which illustrates their environmental specialization for thermoregulation in cold water. However, there is evidence that is inconsistent with this view ${ }^{2}$.

The perception that pinnipeds (seals, sea lions, fur seals and walrus) and cetaceans (whales, dolphins and porpoises) have BMRs twice as high as similar sized animals is an idea that has been widely accepted for decades. It primarily arises from comparisons of marine with terrestrial mammal data.

In his studies, Kleiber was very specific about the conditions under which BMR measurements should be made, in a bid to reduce variance between comparisons of basal rates in animals of different size and from different taxonomic groups.

(Measurements should be made on mature animals in a post-absorptive state, nonreproductive, at thermoneutral ambient temperatures, and without abnormal activity $^{2}$.) For these reasons, Kleiber rejected the use of the two determinations for marine mammal BMR available to him when preparing his original paper.

Nevertheless, published BMR data for marine mammals often have not conformed to these criteria, but have been included in comparative analyses with data that do. This has led to the widely held view that marine mammals have higher BMRs and that they are therefore not 'normal' mammals.

In the analysis by Lavigne et al. ${ }^{2}$, where data from studies on seals and whales were excluded when determinations did not fulfil Kleiber's criteria, it appears that metabolic rates of marine mammals were indistinguishable from those predicted for other mammals under similar conditions. In support of this conclusion, the best available data on minke whale

(Baleanoptera acutorostrata) metabolic rates, determined from field tracking studies and heat loss determinations ${ }^{3}$, give a value at zero swimming speed only 17 per cent greater than the BMR value predicted from Kleiber's general equation.

Clearly, these studies suggest that Kleiber's relationship applies just as well to marine mammals as to terrestrial species.

\section{David W. Sims}

Department of Zoology, University of Aberdeen, Aberdeen AB24 2TZ, UK

1. Nature 403, 597 (2000).

2. Lavigne, D. M. et al. Can. J. Zool. 64, 279-284 (1986).

3. Blix, A. S. \& Folkow, L. P. Acta Physiol. Scand. 153, 61-66 (1995).

\section{Persian role in flowering} of Islamic science

Sir - Giovanni Bignami in his Millennium Essay (Nature 404, 227; 2000) qualified two Persian thinkers, Avicenna and Omar Khayyàm, as belonging to the Arabic world. Occidental writers frequently take "Muslim" to mean "Arab" and consider Islamic culture to be Arabic. Yet even 1,000 years ago the Islamic world was composed of people of quite different origins. Many of the thinkers who participated in the blossoming of science at that period were in fact Persians and not Arabs. Saadi Khochbin

INSERM U309, Institut Albert Bonniot, 38706 La Tronche Cedex, France

Erratum The number of signatories to the letter "Distinguished scientists back Germany's DFG..." (Nature 404, 922; 2000) is 1,641 - not 1,164 , as stated in the correspondence. Nature apologizes for this error. 